\title{
HERMENÉUTICA Y RACIONALIDAD JURÍDICA
}

\author{
MAURICIO RENGIFO GARDEAZÁBAL
}

This article is a contribution to the study of the reasoning done by lawyers in their everyday dealings. The essay's thesis is that a correct description of legal practice must take into account the interpretative context in which lawyers participate. This context comes from a tradition of biblical hermeneutics developed mainly by Protestantism. In this article, legal rationality is understood as the result of a combination of different disciplines that make up that tradition.

El Derecho no es en absoluto una ciencia natural. Los hechos jurídicos referidos por los abogados no se estudian en los laboratorios ni se les somete a experimentación. Las leyes que mencionan los jueces y litigantes en poco o en nada se parecen a las leyes de la naturaleza porque los hechos sociales no siempre se acomodan a sus mandatos. El Derecho tampoco es una ciencia formal como las matemáticas. Las compilaciones normativas contenidas en constituciones o códigos, no permiten demostraciones rigurosas de teoremas o corolarios y los juicios ante los tribunales no se ocupan de las pruebas en el mismo sentido en que lo hacen los estudiantes de matemáticas. Podría pensarse, en consecuencia, que la forma como argumentan los abogados carece de interés debido a la distancia que media entre la jurisprudencia y las ciencias estrictas. Similarmente, podría concluirse que el grado de complejidad de la argumentación jurídica es tan básico, que los abogados no necesitan para su ejercicio profesional, nada distinto de lo que pueden averiguar por sí mismos en su práctica cotidiana.

Ninguna de las dos conclusiones es correcta. Prueba de que la argumentación jurídica resulta interesante para todos, es la constante presencia de 
la opinión pública en la forma como se conducen las audiencias judiciales y en el escrutinio frecuente de la sociedad civil respecto del contenido o fundamento de los fallos judiciales. Hay que reconocer que en parte, la curiosidad es excitada por los intereses que se ponen en juego ante los tribunales. Pero hay también algo de interés genuino por la argumentación misma, por la creatividad y el encanto que encierran por sí mismos los alegatos y defensas judiciales. Prueba de que la argumentación jurídica exhibe cierto grado de complejidad, está en las dificultades que se le atraviesan a los especialistas, en su intento por capturar las sutilezas y detalles del razonamiento judicial. Desde la lógica silogística, pasando por la lógica matemática clásica, la nueva retórica, la tópica, la lógica informal, hasta las lógicas modales deónticas, se han puesto a prueba innumerables modelos de argumentación jurídica sin que aún hoy sea posible concluir que tenemos un esquema claro sobre lo que sucede con el razonamiento jurídico.

En esta breve charla, quisiera unirme al grupo de aquellos que han intentado dilucidar el alcance de la argumentación jurídica, proponiendo una concepción alternativa de la forma como debemos entender el problema. Sostengo que la mejor forma de dilucidar esta difícil cuestión es describir de qué manera suelen proceder los abogados cuando necesitan justificar sus creencias como paso previo a la elaboración de los modelos. La descripción que ensayaré ahora, incompleta y fragmentaria, intentará probar que los rasgos particulares de la argumentación jurídica proceden de la tradición hermenéutica construida y desarrollada en la modernidad. La descripción que ensayaré, no partirá de la práctica aislada de un abogado o de una muestra estadística. En estricto sentido, lo que describiré es una serie de prácticas históricas heredadas por los abogados de generación en generación y que está relacionada con la forma como se leen los textos jurídicos a partir de la reforma protestante. He dividido este trabajo en dos partes. En la primera parte, reconstruiré los procedimientos argumentativos de la tradición hermenéutica que se aplicaron fundamentalmente para solucionar importantes problemas religiosos. En la segunda parte, intentaré conectar esta tradición con el problema de la argumentación jurídica. Sostendré que la reconstrucción de la racionalidad en el Derecho, debe efectuarse desde la perspectiva particular de la hermenéutica.

La hermenéutica es un conjunto de disciplinas antes que un cuerpo unificado de conocimientos. Las disciplinas que la conforman se agruparon sistemáticamente para hacer frente a serias dificultades de interpretación de los 
textos sagrados. Tales disciplinas son: la gramática, la crítica, la retórica y la dialéctica. Precisemos esto un poco más. A comienzos del siglo dieciséis, los protestantes iniciaron su rebelión en contra de las autoridades eclesiásticas, tachándolas de corruptas y pervertidas. El centro de su argumentación consistía en que la Iglesia Católica no era necesaria para acceder a la revelación de la doctrina cristiana. Para acceder a esta revelación, bastaba con la lectura directa del texto bíblico. Su planteamiento suponía que era posible encontrar el sentido de los textos sin mediación alguna del magisterio. De acuerdo con la nueva doctrina protestante, la Biblia carecía de lagunas. Sin embargo, los protestantes tenían que reconocer que el texto bíblico plantea muchas dificultades. Mencionemos algunas de ellas. Primero, el hebreo antiguo desapareció como lengua viva hacía varios siglos. Lo mismo sucede con el griego clásico. Segundo, incluso aprendiendo el idioma, el hebreo antiguo presenta dificultades adicionales. No tiene vocales, es ambiguo según la posición de sus letras y se presta a múltiples interpretaciones. Tercero, no hay noticia cierta sobre los manuscritos originales ni modo concreto para determinar la autenticidad de los textos actuales. Cuarto, los textos no están fijos mediante la separación en capítulos y libros. Además, tenemos que recordar que la ortografía, con todo su arsenal de puntos y comas, no existía en aquel tiempo.

Estas razones, entre muchas otras, servían de fundamento al catolicismo para afirmar que la Biblia no era toda la revelación y que ésta necesitaba de complemento por parte de la tradición eclesiástica. La respuesta del protestantismo, fue la creación de la gramática hebrea y la reunión de esta disciplina con la crítica, la retórica y la dialéctica, para enfrentar el desafío: entender los textos sagrados por sí mismos, sin mediación de la iglesia. La reunión de estas disciplinas se denominó hermenéutica. El propósito central de las disciplinas hermenéuticas es permitir la comprensión de un texto desde el texto mismo y no en virtud de consideraciones externas. Expliquemos el papel que cumple cada una de las disciplinas hermenéuticas. La gramática consiste en el estudio de las reglas de formación y transformación que gobiernan el uso de las palabras y la construcción de las frases. En ese entonces resultaba fundamental aprender la gramática de los idiomas hebreo, arameo, griego y latín para solucionar ambigüedades, vaguedades e indeterminaciones de los textos

Consideremos a manera de ejemplo, algunas frases vagas y ambiguas de la Biblia, con el propósito de ilustrar un típico procedimiento gramatical': El profeta tenía el espíritu de Dios, Dios infundió su espíritu a los hombres, los hombres

${ }^{1}$ Cfr. Spinoza, Baruch. Tratado Teológico-Político. Madrid: Alianza, 1994. Mi interpretación es ligeramente distinta de la planteada por Espinosa pero me baso en su selección de textos. 
están repletos del espíritu de Dios. El problema gramatical sería entonces ¿Qué quiere decir en la Biblia Espíritu de Dios? ¿Qué quiere decir la Biblia cuando se afirma que los profetas expresan el Espíritu de Dios o que los apóstoles han sido visitados por el Espíritu Santo?

La solución consiste en ilustrar, palabra por palabra, frase por frase, los distintos sentidos de las frases, tal y como se usan en la Biblia. La primera palabra problemática es entonces espíritu. La palabra hebrea para espíritu es ruagh y se caracteriza por su gran ambigüedad. Los siguientes casos son usos de la palabra tal y como aparecen en el antiguo testamento:

1. Aliento. Salmos, 135, 17: ni espíritu hay en su boca.

2. Ánimo o respiración. Samuel I, 30, 12: y le volvió el espíritu.

3. Valentía y fuerzas. Josué 2, 11: después ya no hubo espíritu en ningún varón.

Ezequiel 2, 2: y me vino el espiritu que me permitió sostenerme sobre mis pies.

4. Virtud y aptitud. Job, 32, 8: ciertamente que el espíritu mismo está en el hombre.

5. Opinión. Números 14, 24: porque tuvo otro espíritu.

6. Las partes del mundo, los lugares de donde viene el viento.

Ezequiel 37, 9: el espíritu descendió del norte.

7. Alma. Eclesiastés 3, 19: el espíritu es el mismo para todos.

La segunda expresión problemática es el atributivo de Dios. De nuevo, el procedimiento consistiría en averiguar sus distintos usos en el texto bíblico. Así, las cosas son de Dios en los siguientes sentidos:

1. Partes: Ojos de Dios.

2. Bajo su poder: Cielos de Dios.

3. Dedicado a Él: Pan de Dios, Templo de Dios.

4. Trasmitido por los profetas: Leyes de Dios, reglas de Dios.

5. Superlativo: Montes de Dios, Cedros de Dios, Miedo de Dios,

Hijos de Dios, el viento de Dios se movía sobre las aguas.

Con base en el análisis anterior, sería posible desambiguar y precisar los sentidos de muchas frases, como por ejemplo, las que aparecen en Éxodo 31, 3: Lo llenaré del espíritu de Dios (a Besalel); Samuel I, 16, 14: espíritu malo de Dios (a Saúl) y Nehemías 9, 20: Tú le has dado tu buen espíritu para hacerlos entender. El examen minucioso de la gramática bíblica permite establecer, al menos en lo que al antiguo testamento se refiere, que la expresión espíritu de Dios era una expresión que servía para calificar a una persona como exitosa o afortunada en 
algún punto. Por ejemplo, si fuese posible congratular a un israelita por el nacimiento de un hijo o la culminación de una empresa, sería apropiado decirle que estuvo rodeado por el espíritu de Dios.

La crítica hizo su aparición un poco antes que la gramática como resultado de las dificultades en los procesos de edición y reproducción de los manuscritos originales. Consiste en la fijación de los textos por medio de la ortografía creada por los críticos- y la glosa. El crítico ejerce su labor confrontando ediciones, traducciones, manuscritos auténticos y copias adulteradas en palimpsestos, tablillas de barro, papiros, etc. Como resultado de este proceso, el lector puede hacerse a una idea sobre la forma de composición del texto (si es una fusión de versiones, si es hecho por varios autores, etc.), el grado de autenticidad que posee, la confiabilidad de la traducción, las posibles interpolaciones, etc. La crítica bíblica también es muy importante porque permite conservar la integridad de la obra y reconstruir la forma como se llegó a su composición actual. Nuevamente, y a manera de ilustración, se considerará un problema típico de la crítica bíblica. De acuerdo con la tradición católica, el autor del Pentateuco es Moisés. Tal cosa no aparece referida en la Biblia pero, de acuerdo con los principios del catolicismo, la lectura de las Sagradas Escrituras debe efectuarse por medio de la tradición conservada por el magisterio. La crítica protestante, por el contrario, omite esta consideración y se plantea nuevamente la pregunta por la autoría del Pentateuco ¿Quién escribió el Pentateuco? ¿Es Moisés autor de los cinco libros? La respuesta de la crítica es que tal cosa no parece posible a la luz de la consideración misma de los textos ${ }^{2}$. Por ejemplo, en Deuteronomio 1, 1-5 se dice que Moisés no pasó el Jordán. En Deuteronomio 27: se dice que el libro de Moisés está escrito en la superficie de un altar, lo cual no parece posible respecto de una obra tan extensa como el Pentateuco y sugiere que Moisés mismo pudo componer otro texto, más breve, pero distinto al que se le atribuye. En Números 12, 3 se dice que Moisés era el más humilde de todos los hombres; lo cual hace pensar que Moisés no pudo haber escrito esta frase sin contradecirse pragmáticamente. Finalmente, en Deuteronomio 34, 5, 10 se establece que Moisés, siervo de Dios, murió, nunca existió en Israel un profeta como Moisés; frase que de no ser una interpolación, por razones obvias tampoco pudo haberla escrita el mismo Moisés. Por otra parte, algunos textos del Génesis refieren alguno episodios históricos que hacen pensar que la obra fue compuesta muchos años después de la muerte de Moisés, como Génesis 12, 6, donde se hace alusión a la época en que estaban los cananeos en la Tierra Prometida. Parejamente, se usan denominaciones para accidentes geográficos o ciudades que no se conocían, al menos no de esa forma, en los tiempos de

\footnotetext{
${ }^{2}$ En este punto sigo nuevamente a Spinoza.
} 
Moisés, como en Génesis 22, 14, cuando se Alude al monte Moria, o en Génesis 14, 14, cuando Abraham persiguió a sus enemigos hasta Dan. El estudio del texto contradice la tradición católica y prueba que la verdadera fuente de la revelación es la Biblia y no el magisterio.

La retórica es el estudio de la comunicación efectiva o exitosa. El dominio de la retórica, hace posible una comunicación más fluida que la natural, haciendo menos parsimoniosa o más pertinente la exposición. Es el arte de clarificar los discursos. La retórica ha sistematizado una serie de figuras del pensamiento y la dicción que sirven como caja de herramientas tanto para aquel que se expresa como para aquellos que escuchan. Las figuras más conocidas son: la metáfora, la metonimia, el ejemplo, la sinécdoque, la analogía, etc. La retórica se utiliza para facilitar la comprensión de los textos más difíciles de la Biblia, en especial, de aquellos que recurren a historias inverosímiles o parábolas de contenido complejo. Por ejemplo, en Lucas 15, se recogen tres parábolas de Jesús. Las tres historias tratan aparentemente de temas diferentes: la pérdida y posterior hallazgo de un dracma, el extravío de una oveja y el reencuentro con su pastor, el viaje del hijo pródigo y el reencuentro con su padre. Las tres historias pueden conectarse de muchas formas: la pérdida y posterior hallazgo del objeto perdido, la alegría del reencuentro, el mayor valor de lo que ha sido recuperado frente a lo que se ha conservado, etc. ¿Cómo interpretar las tres historias? La retórica recomienda estudiar el auditorio para entender por qué se han seleccionado estas historias. Es obvio que se trata de situaciones cotidianas que suceden en los sectores rurales o en los hogares más comunes. En este caso, Jesús utiliza la figura retórica de la metáfora para realizar una comparación implícita entre la situación del pecador que se ha perdido con la moneda extraviada, la oveja perdida o el hijo pródigo. Lo misma comparación se establece entre la dueña de la casa, el pastor o el padre, con Dios, entendido como Padre o Maestro de la humanidad. Lo que muestran los ejemplos es que la misericordia referida al perdón de los pecados, son actos que encierran gran valor personal y emocional. La enseñanza de Jesús es, en este caso, y en contra de la creencia religiosa de su tiempo, que Dios perdona los pecados. Por extensión del mandamiento del amor establecido por Jesús, esto implica que debemos perdonar a todos nuestros semejantes. La retórica dilucida de esta forma particular, tres textos aparentemente inconexos.

La dialéctica griega es un juego de preguntas y respuestas entre dos personas. La persona que contesta pierde si se contradice y gana si sale adelante. Con el tiempo, este juego se transformó en todo un método pedagógico de formación en filosofía y moral. Sin duda, la dialéctica inspiró a los filósofos para crear y desarrollar la lógica formal. La aplicación de la dialéctica a los problemas de interpretación, consiste en que el lector plantee preguntas al texto escrito en 
lugar de hacerlas al autor. El lector mismo intenta asumir el lugar del autor y responde la pregunta basándose exclusivamente en lo escrito. El objetivo de este ejercicio es quedarse con las interpretaciones que no incurren en contradicciones o que hacen rendir más al texto, y desechar aquellas que traen consigo inconsistencias o lagunas. El resultado de la lectura dialéctica, es extraer algunos principios generales de lectura que sintetizan el conjunto de una obra, que permiten apreciarla de manera general y que resultan confiables a futuro para evitar contradicciones y vacíos. En los textos sagrados, son frecuentes las contradicciones debido a que se trata de compilaciones producidas por muchos autores y es preciso sistematizar los contenidos para conferirle sentido a la totalidad de la obra. Por otra parte, Jesús propuso interpretaciones anagógicas de la ley de Moisés que parecen contradecir algunas creencias básicas de los hebreos. Por ejemplo, la ley establece que la mujer adúltera debe se lapidada, y sin embargo, Jesús dijo que sólo aquel que estuviera limpio de pecado podía ejecutar la sanción. ¿Hay una contradicción real entre ambas tradiciones? Otro caso de contradicción aparente ocurre por el hecho de que la ley parece haber sido instituida para la salvación de los judíos y no para salvación de toda la humanidad, precisamente cuando Moisés estableció un pacto con Dios y el pueblo Israelita se comprometió a cumplir los diez mandamientos. La dialéctica ensayará una interpretación sistemática de la Biblia con el propósito de resolver las diferencias. Así por ejemplo, señalará respecto de esta última diferencia que en Lucas 7, 1; Lucas 10, 29; Juan 4 y Gálatas 3 a 5, existe suficiente evidencia textual para disipar las contradicciones. Por ejemplo, señalando que antes de la alianza de Moisés se había establecido una promesa previa entre Dios y Abraham que tiene preeminencia sobre el pacto posterior, y que esta promesa de redención beneficiaria a toda la humanidad y no solamente al pueblo judío.

En este punto cabe preguntarse qué le puede dar unidad a esta agrupación de disciplinas. ¿Tiene sentido hablar de la hermenéutica como algo distinto de las disciplinas que la integran? La verdad es que la unidad de la hermenéutica depende de que se pueda demostrar la existencia de cierta conexión necesaria entre cada una de las disciplinas. Creo que la argumentación que permite probar está conexión sería más o menos del siguiente estilo: la gramática requiere de la crítica para poder practicarse porque no tendría sentido estudiarla en textos adulterados. Pero la crítica requiere de la gramática para poder establecer si un texto es auténtico. Además, la crítica y la gramática no pueden operar si no logran establecer qué quiere decir un pasaje cuando no es prima facie eficaz. Para ello requieren de la retórica. Pero al mismo tiempo, la retórica precisa de la crítica y la gramática para determinar el tipo de figura que se está utilizando. Finalmente, la gramática, la crítica y la retórica deben armonizarse en todo aquello que parezcan contradecirse, por medio de la dialéctica. Sin 
embargo, la dialéctica necesita las demás disciplinas para poder proporcionar soluciones adecuadas a las inconsistencias. Este refuerzo mutuo es lo que le presta unidad a todas las disciplinas y es lo que justifica la hermenéutica como disciplina especial destinada a la interpretación de los textos bíblicos y de los textos en general.

\section{II}

La tradición hermenéutica constituida durante la reforma protestante, fue incorporada por los romanistas italianos y alemanes al estudio de las fuentes del Derecho. Antes de las grandes codificaciones, las fuentes del Derecho eran principalmente las disposiciones de los monarcas, las sentencias de los tribunales, el derecho consuetudinario de las regiones, la legislación canónica y naturalmente, el Derecho Romano. El estudio del Derecho Romano en sus fuentes, era esencial en la formación de los juristas profesionales. Para acceder al Digesto, El Código y las Novelas, se requería el dominio de las mismas disciplinas empleadas en la interpretación bíblica. De esta forma, la gramática se ocupaba del estudio del latín, la crítica fijaba el texto confrontando los manuscritos originales, la retórica servía para corregir impropiedades o llenar lagunas y la dialéctica, para dotar de unidad y universalidad a los materiales. El ensayo pionero más influyente sobre hermenéutica de las fuentes del Derecho es el capítulo cuarto del Sistema de Derecho Romano Actual, escrito por Savigny, quien lideró la Escuela Histórica del Derecho en Alemania. Al parecer, el título preliminar del Código Civil, que regula el tema de la interpretación en Chile y en Colombia, sería un resumen del capítulo cuarto citado, confeccionado de forma apresurada por don Andrés Bello. En este punto conviene examinar los elementos de la hermenéutica jurídica. El elemento literal en Derecho, consiste en la misma gramática de la tradición hermenéutica. Sirve para disolver las ambigüedades, vaguedades e indeterminaciones de los textos legales. Por ejemplo, en nuestra legislación, el artículo 2534 del código civil colombiano establece que:

La sentencia judicial que declara una prescripción hará las veces escritura pública para la propiedad de bienes raíces o de derechos reales constituidos en ellos; pero no valdrá contra terceros sin la competente inscripción.

Y el artículo 758 dispone:

Siempre que por una sentencia ejecutoriada se reconociere como adquirido por prescripción el dominio o cualquier otro de los derechos mencionados en los precedentes artículos de este capí- 
tulo, servirá de título esta sentencia después de su registro en la oficina $\mathrm{u}$ oficinas respectivas.

Los textos citados han suscitado polémica entre los abogados que sostienen que las sentencias judiciales no pueden ser títulos de los derechos de propiedad y los que defienden la posición contraria. Los defensores de la primera interpretación usan un argumento gramatical para defender su posición. Su forma de proceder es la siguiente. Se preguntan, ¿En qué sentido se usa en el código la palabra título? Al registrar los diferentes usos posibles de título, citan el artículo 1960 del código donde la acepción alude al documento probatorio y no al acto jurídico. A continuación, concluyen que el mismo uso se hace en los artículos citados, razón por la cual las sentencias no son títulos en tanto actos jurídicos sino en tanto documentos probatorios de la prescripción.

El elemento histórico es la crítica de la interpretación bíblica. Normalmente supone el estudio de los proyectos de ley, las actas y ponencias que dieron lugar a las normas vigentes. Un ejemplo de aplicación práctica de la crítica lo encontramos a propósito del extenso y difícil artículo 1297 del código civil que establece:

Si dentro de quince días de abrirse la sucesión no se hubiere aceptado la herencia o una cuota de ella, ni hubiere albacea a quien el testador haya conferido la tenencia de los bienes, y que haya aceptado su encargo, el juez, a instancia del cónyuge sobreviviente, o de cualquiera de los parientes o dependientes del difunto, o de otra persona interesada en ello, o de oficio, declarará yacente la herencia; se insertará esta declaración en el periódico oficial del territorio si lo hubiere; y en carteles que se fijarán en tres de los parajes más frecuentes del distrito en que se hallen la mayor parte de los bienes hereditarios, y en el del último domicilio del difunto; y se procederá al nombramiento de curador de la herencia yacente. Si hubiere dos o más herederos, y aceptare uno de ellos, tendrá la administración de todos los bienes hereditarios proindiviso, previo inventario solemne; y aceptado sucesivamente sus coherederos, y suscribiendo el inventario tomarán parte en la administración. Mientras no hayan aceptado todas las facultades del heredero o herederos que administren, serán las mismas de los curadores de la herencia yacente; pero no serán obligados a prestar caución, salvo que haya motivo de temer que bajo su administración peligren los bienes.

En este caso, los críticos del código, han encontrado que el último párrafo del artículo, es una mala trascripción del código civil chileno que puede ser 
fácilmente corregida mediante la adición de una coma, de modo que el original pasaría de:

Mientras no hayan aceptado todas las facultades del heredero o herederos que administren, serán las mismas de los curadores de la herencia yacente

a disponer que:

Mientras no hayan aceptado, todas las facultades del heredero o herederos que administren, serán las mismas de los curadores de la herencia yacente

El mal llamado elemento lógico, es la retórica de la hermenéutica bíblica. Un ejemplo clásico del uso de figuras retóricas en el código civil colombiano, son los artículos 696 y 697 que establecen respectivamente que:

Las abejas que huyen de la colmena y posan en árbol que no sea del dueño de esta, vuelven a su libertad natural, y cualquiera puede apoderarse de ellas y de los panales fabricados por ellas, con tal que no lo haga sin permiso del dueño en tierras ajenas, cercadas o cultivadas, o contra la prohibición del mismo en las otras; pero al dueño de la colmena no podrá prohibirse que persiga a las abejas fugitivas en tierras que no estén cercadas ni cultivadas.

Las palomas que abandonan un palomar y se fijan en otro, se entenderán ocupadas legítimamente por el dueño del segundo, siempre que éste no se haya valido de alguna industria para atraerlas y aquerenciarlas. En tal caso estará obligado a la indemnización de todo perjuicio, incluso la restitución de las especies, si el dueño la exigiere y si no la exigiere, a pagarle su precio.

¿Qué quieren decir estos ejemplos? Ambos textos son usos característicos de la figura retórica del ejemplo y pretenden hacer entender a los lectores una regla muy simple que rige a propósito de la adquisición de la propiedad mediante el modo de la ocupación. La regla es muy sencilla: los animales bravíos, por oposición a los domésticos, son del dueño de las jaulas, pajareras, conejeras, colmenas, estanques o corrales en que estuvieren encerrados, pero vuelven a su libertad natural cuando recobran su libertad. 
Finalmente, el elemento sistemático es la dialéctica, tal y como se empleaba en la hermenéutica bíblica. Consiste en armonizar los textos legales mediante la sistematización de sus contenidos. Un ejemplo de contradicción aparente está en el artículo 765 del código civil que establece:
El justo título es constitutivo o traslaticio de dominio. Son cons- titutivos de dominio, la ocupación, la accesión y la prescripción. Son traslaticios de dominio los que por su naturaleza sirven para transferirlo, como la venta, la permuta, la donación entre vivos. Pertenecen a esta clase las sentencias de adjudicación en juicios divisorios y los actos legales de partición. Las sentencias judiciales sobre derechos litigiosos no forman nuevo título para legitimar la posesión. Las transacciones en cuanto se limitan a reconocer o declarar derechos preexistentes no forman nuevo título; pero en cuanto transfieren la propiedad de un objeto no disputado, constituyen un título nuevo.

Como puede apreciarse, el código civil establece que los títulos justos pueden ser constitutivos o traslaticios. Si hay títulos traslaticios, esto significa que un acuerdo de voluntades basta para transferir la propiedad. Sin embargo, más adelante el código señala que la venta y el arrendamiento de cosa ajena son válidos, cosa imposible en un sistema jurídico que permite los títulos traslaticios. Si los títulos son traslaticios, la venta de cosa ajena debería ser nula. ¿Cómo resolver esta contradicción? La respuesta es sencilla. No hay que leer el texto separadamente sino en forma conjunta. La primera frase, que ha sido catalogada como problemática, en realidad aparece explicada por las siguientes. Es muy sencillo entonces, apreciar que los ejemplos de títulos constitutivos y traslaticios, son en realidad modos. La primera frase hace referencia es a los modos y no a los títulos. En lugar de leer:

El justo título es constitutivo o atributivo de dominio.

Habría que leer:

El modo es constitutivo o atributivo de dominio.

De lo contrario, el ordenamiento jurídico sería contradictorio. 


\section{III}

Concluyo entonces que la hermenéutica jurídica no es otra cosa que una adaptación de la hermenéutica general inspirada en la interpretación bíblica. ¿Qué importancia tiene esta conclusión para el tema que nos convoca? Para responder esta pregunta es preciso señalar que la argumentación jurídica está centrada esencialmente en la aplicación e interpretación de textos a casos concretos. Lo que los jueces y abogados hacen cotidianamente es resolver desacuerdos jurídicos, y lo hacen, conciente o inconscientemente, aplicando sus conocimientos hermenéuticos. Si la argumentación jurídica está inscrita en el problema de la interpretación y comprensión de textos, es preciso recuperar el contexto hermenéutico para reconstruir la racionalidad jurídica.

Nótese que la exigencia de recuperar el contexto hermenéutico, asume que por alguna razón la tradición hermenéutica se ha perdido. ¿En qué consiste esta pérdida del contexto hermenéutico? En mi concepto el problema del olvido del contexto hermenéutico se produjo por las siguientes razones. Para empezar, las disciplinas que constituían la hermenéutica continuaron su desarrollo conceptual, dejando para después la cuestión de su relación mutua. Así, la gramática se convirtió en la rama principal de la lingüística estructural y de la lingüística generativa; la crítica y la retórica del ornato, dieron lugar a la teoría literaria y la semiótica; la retórica de la invención y la dialéctica, inspiraron las investigaciones lógicas que dieron lugar a la lógica moderna, la nueva retórica, la tópica, la pragmática y la lógica informal. Las transformaciones que sufrieron estas disciplinas permitieron aplicar sus técnicas a nuevos frentes y el problema de la interpretación pasó a segundo plano. Ampliadas y transformadas de esta forma, dejó de ser obvio para los expertos la asociación de estas disciplinas a la comprensión de textos. La especialización rompió los vínculos que gestaron la unidad disciplinar de la hermenéutica.

Lo cierto es que en nuestro tiempo, el problema de la interpretación continúa vigente y sigue siendo válido congregar diferentes disciplinas para enfrentarlo. Si fuera preciso reunir diversas disciplinas para tratar el problema de la interpretación en nuestro tiempo, creo que sería incorrecto volverlas a reunir en su totalidad. De nada serviría poner a un lado la gramática generativo transformacional, las lógicas matemáticas, la semiótica y la teoría literaria. Mucha partes son tan complejas que un abogado ya no tendría tiempo para estudiarlas a todas. En la vida práctica, no le alcanzaría el tiempo para realizar un estudio detallado de lógica modal 
deóntica y teoría literaria de la recepción. Lo que parece correcto en este caso es reunir aquellas piezas de cada una que se refieran a la interpretación, para formar un instrumental que preste alguna utilidad a los abogados. En ese sentido, propongo tomar de la lingüística los estudios sobre gramática informal y la teoría de la traducción; de la nueva retórica, las investigaciones sobre disposición y ornato; de la lógica matemática, la noción de validez; de la lógica informal, las convenciones para reconocer argumentos; de la tópica, la clasificación y estudio de las falacias y así sucesivamente. ¿Cuál sería el resultado? ¿Un híbrido inmanejable? En realidad creo que no sucedería nada distinto de lo que sucedió en el pasado. Tendríamos hermenéutica y nada más que eso, es decir, una disciplina interdisciplinaria propia de todos los estudios culturales que están relacionados con la interpretación de textos, la herramienta característica de los abogados del pasado, del presente y del futuro.

\section{Bibliografía}

Dilthey, Wilhem. Esbozos para una Crítica de la Razón Histórica. Madrid: Istmo, 2000. Gadamer, Hans Georg. Verdad y Método. Salamanca: Sígueme, 2001.

Jauss, Hans Robert. Las Transformaciones de lo Moderno. Madrid: Visor, 1995.

Ricoeur, Paul. Hermeneutics and The Human Sciences. Cambridge University Press, 1981.

Spinoza, Baruch. Tratado Teológico-Político. Madrid: Alianza, 1994.

Vattimo, Gianni. Hermenéutica y Racionalidad. Bogotá: Norma, 1994. 